${ }^{13}$ Wolman, A. A., and Wilson, jun., A. J., Pesticides Monit. J., 4, 8 (1970).

14 Peakall, D. B., Nature, 216, 505 (1967).

15 Anderson, D. W., Hickey, J. J., Risebrough, R. W., Hughes, D. F., and Christensen, R. E., The Canadian Field Naturalist, 83, 91 (1969).

${ }^{16}$ Keith, J. O., Woods, jun., L. A., and Hunt, E. G., Trans. Thirtyfifth North American Wildlife and Natural Resources Conference, 56 (Wildlife Management Institute, Washington, 1970).

17 Ratcliffe, D. A., Nature, 215, 208 (1967).

18 Ratcliffe, D. A., J. Appl. Ecol., 7, 67 (1970).

19 Levin, W., Welch, R. M., and Conney, A. C., Fed. Proc., 27, 649 (1968).

20 Bitman, J., Cecil, H. C., Harris, S. J., and Fries, G. F., Science, 162, 371 (1968).

21 Brownell, R. L., and Le Boeuf, B. J., in Biological and Oceanographical Survey of the Santa Barbara Channel Oil Spill, 19691970 (edit. by Straughan, D.), 287 (Allan Hancock Foundation, Univ. of Southern California, 1971).

22 Friend, M., and Trainer, D. O., Science, 170, 1314 (1970).

23 Friend, M., and Trainer, D. O., J. Wildlife Dis. (in the press).

24 Stickel, L. F., Stickel, W. H., and Christensen, R., Science, 151, 1549 (1966).

25 Odell, D. K., Proc. Seventh Ann. Conf. Biol. Sonar and Diving Mammals, Stanford Research Institute, Menlo Park, California, October 23-24, 1970 (in the press).

\section{Light Flashes produced in the Human Eye by Extremely Relativistic Muons}

IT is generally agreed that the light flashes observed by astronauts on Apollo missions $11-14^{1}$ were produced by the passage of heavy cosmic ray nuclei through the eye. The exact mechanism has been a subject of some controversy, however, most workers leaning towards either Cerenkov radiation $^{2-4}$ or direct ionization and excitation of molecules at the retina ${ }^{1,5,6}$. Light flashes similar to the Apollo observations have been reported to result from irradiations of the eyes by X-rays ${ }^{5,7}$, neutrons ${ }^{5,6,9,10}$ and slow alpha particles ${ }^{8}$, all of which are more likely to involve ionization and excitation than Cerenkov radiation. Early indications that the human eye might be sensitive to individual relativistic singly charged particles $^{11}$ have not been borne out by calculations ${ }^{3}$ or by recent observations ${ }^{5}$.

This report describes a test of the ability of the human eye to detect Cerenkov radiation when it is generated with sufficient intensity by the passage of a burst of relativistic charged particles through the vitreous humour and retina of the eye. The small values of LET and total dose involved in producing the bright extended flashes described below seem to rule out any significant contribution from direct ionization and excitation. All observations were made during two short periods of exposure to a beam of $6 \pm 2 \mathrm{GeV} / \mathrm{c}$ muons at the Brookhaven AGS. Red X-ray dark adapting goggles were worn for at least $0.5 \mathrm{~h}$ before exposure and observations were made in a completely darkened state under improvised cloth and leather hoods with the muons entering the eye through the side of the head. The muons arrived spread over pulses of $440 \mathrm{~ms}$ duration with a time interval of $2 \mathrm{~s}$ between pulses. The flux density of muons in each pulse was approximately $3 \times 10^{3}$ muons $\mathrm{cm}^{-2}$.

The phenomena appeared as bright diffused flashes which appeared and disappeared with the beam pulses and seemed to fill the periphery of the field of view but never the entire field of view. When I turned away from the beam so that it entered from the rear of the head, the flashes were no longer clearly distinguishable. The coincidences between announced flashes and the beam pulses were checked as well as my ability to tell when my eyes were centred in the active beam.

Localized areas of the retina function as units at threshold levels of signal. The areas of these summation units range from $10^{-6} \mathrm{~cm}^{2}$ at the fovea to about $9 \times 10^{-4} \mathrm{~cm}^{2}$ on the periphery with an average of roughly $8 \times 10^{-5} \mathrm{~cm}^{2}$. Signals generated in a unit within an interval of $0.1 \mathrm{~s}$ are effectively in coincidence. The number of such coincidences required to induce a visual sensation is somewhere between two and twenty, ten being typical of most measurements ${ }^{12}$.

There is some possibility that the flashes observed in this experiment are similar in origin to the haze reported in X-ray ${ }^{5.7}$ and neutron ${ }^{6}$ irradiations of the eye, phenomena that would certainly not involve Cerenkov, radiation. But the flux rate that resulted in bright extended flashes corresponds to the passage of three muons per pulse through a $9 \times 10^{-4} \mathrm{~cm}^{2}$ summation unit on the periphery or less than 1 in each $0.1 \mathrm{~s}$ interval of beam. This rate of dose, $0.026 \mathrm{mr}$ in $0.1 \mathrm{~s}$, is a factor of ten smaller than the X-ray doses over the same or shorter intervals that were required for even a slight haze $e^{5,7}$ despite the similarly low LET associated with both radiations. Moreover, the $10 \mathrm{~s}$ persistence reported for the neutron produced haze ${ }^{6}$ was not observed in this experiment.

On the other hand, the number of "visible" ${ }^{3}$ Cerenkov photons in each $0.1 \mathrm{~s}$ of pulse that can be expected to accompany the muons through the retinal summation units has been calculated ${ }^{13}$ as 40 on the periphery, 0.1 at the fovea and about 4 for a unit of average area. If we assume the probability of absorbing each photon incident on the periphery to be $20 \%$, the value measured at $10^{\circ}-20^{\circ}$ eccentricity ${ }^{14,15}$, then a threshold value of ten absorbed photons should be exceeded in the muon experiment for $26 \%$ of the peripheral units in each $0.1 \mathrm{~s}$ interval of the $0.44 \mathrm{~s}$ pulse and essentially nowhere else on the retina. Although calculations of this type are necessarily crude as a result of our incomplete knowledge of the peripheral region of the retina, they do indicate Cerenkov radiation as the most plausible mechanism for producing the flashes described above.

I thank members of the Columbia, Harvard, National Accelerator Laboratory, and Rochester University collaboration who designed and operated the muon facility at the Brookhaven AGS for help, Professor L. Lederman for helpful suggestions and Dr Paul Bottino for help with the observations.

Peter J. McNulty

Space Physics Laboratory,

Air Force Cambridge Research Laboratories,

L. G. Hanscom Field,

Bedford,

Massachusetts 01730

Received May 14; revised July 19, 1971.

1 Chapman, P., Pinsky, L., Benson, R., and Budinger, T., Proc. Nat. Symp. Natural and Manmade Radiation in Space (in the press).

${ }^{2}$ Fazio, G. G., Jelley, J. V., and Charman, W. N., Nature, 228, 260 (1970).

3 Madey, R., and McNulty, P. J., Bull. Amer. Phys. Soc., 15, 1671 (1970); Proc. Nat. Symp. Natural and Manmade Radiation in Space (in the press).

4 McNulty, P. J., and Madey, R., Proc. Nat. Symp. Natural and Manmade Radiation in Space (in the press).

3 Tobias, C. A., Budinger, T. F., and Lyman, J. T., Nature, 230, 596 (1971).

6 Budinger, T. F., Bichsel, H., and Tobias, C. A., Science, 172, 868 (1971).

7 Pape, R., and Zakovsky, J., Fortschr. Gebiete, 80, 65 (1954).

8 Tobias, C. A., Budinger, T. F., and Lyman, J. T., Proc. Nat. Symp. Natural and Manmade Radiation in Space (in the press).

9 Fremlin, J. H., New Scientist, 47, 42 (1970).

10 Charman, W. N., Dennis, J. A., Fazio, G. G., and Jelley, J. V., Nature, 230, 522 (1971).

11 D'Arcy, F. J., and Porter, N. A., Nature, 196, 1013 (1962).

12 Pirenne, M. H., in The Eye, 2 (edit. by Davson, $\mathrm{H}$.) (Academic Press, New York, 1962).

13 McNulty, P. J., Document No. AFCRL 71-0377 (Air Force Cambridge Research Laboratories, 1971).

14 Rushton, W. A. H., J. Physiol., 25, 819 (1942).

15 Rushton, W. A. H., J. Physiol., 30, 134 (1956). 